\title{
ANÁLISE DOS CENTROS DE ATENDIMENTO AO TURISTA EM BELO HORIZONTE/MINAS GERAIS/BRASIL ENTRE OS ANOS DE 2014 E 2018
}

\section{Resumo}

\author{
${ }^{1}$ Solano de Souza Braga \\ ${ }^{2}$ Guilherme Augusto Pereira Malta \\ ${ }^{3}$ Marcos Vinicius Braga da Silva \\ ${ }^{4}$ Maria Flávia Pires Barbosa \\ ${ }^{5}$ André Riani Costa Perinotto
}

Objetivo do estudo: Este trabalho tem como objetivo geral analisar os Centros de Atendimento ao Turista (CATs) em Belo Horizonte, Minas Gerais. Ao realizar um estudo entre os anos de 2014 e 2018, buscou-se compreender em que medida a realização da Copa do Mundo FIFA 2014 contribuiu para a melhoria dos serviços de informação turística na cidade.

Originalidade/Relevância: A informação turística tem papel categórico na promoção de um destino, por consequência, os Centros de Atendimento ao Turista assumem um papel promocional importante, já que concentram informações sobre determinada localidade e sobre os demais destinos turísticos do entorno. A escolha do tema se justifica uma vez que a melhoria dos Centros de Atendimento ao Turista foi definida como uma das áreas prioritárias na Matriz de Responsabilidades, assumida pelos governos municipal e estadual, além de se atentar para a importância de informações turísticas de qualidade para se ter um destino turístico mais inteligente.

Metodologia/abordagem: De caráter exploratório, a pesquisa foi dividida em duas etapas concomitantes, em um primeiro momento foi feito um levantamento bibliográfico sobre o tema e, paralelamente, foi realizada a avaliação da estrutura e dos serviços prestados pelos CATs, por meio de entrevistas e avaliação in loco, realizadas em 2014 , um mês antes da realização da Copa do Mundo FIFA, e em maio de 2018. Os itens analisados foram agrupados, analisados e categorizados em três tópicos: a) "Produto Facilitador"; b) "Produto Suporte"; e c) "Produto Ampliado".

Principais resultados: Após definir os parâmetros de análise e comparar os dados de 2014 e 2018 , pode-se considerar que apresentam uma funcionalidade que, muitas vezes, não condiz com a teoria daquilo que se entende por um CAT, já que tendem a cumprir a função somente de informar o turista e não de cativá-lo. Também foi possível observar que não houve melhorias dos serviços oferecidos pelos CATs após os investimentos realizados em 2014.

Contribuições teóricas/metodológicas: (i) Realizar uma revisão teórica sobre os CATs; (ii) Propor e sistematizar uma forma de análise e avaliação da infraestrutura e os serviços oferecidos; e (iii) Avaliar os legados pós Copa do Mundo FIFA 2014 nessa área.

Palavras-chave: CAT. Informação. Turismo. Copa do Mundo FIFA 2014. Belo Horizonte.

\section{Como referenciar em APA:}

Braga, S., Malta, G., Silva, M., Barbosa, M., \& Perinotto, A. (2019). Análise dos Centros de Atendimento ao Turista em Belo Horizonte/Minas Gerais/Brasil entre os Anos de 2014 e 2018. PODIUM Sport, Leisure And Tourism Review, 8(2), $174-191$. https://doi.org/10.5585/podium.v8i2.323

${ }^{1}$ Universidade Federal do Piauí - UFPI, Piauí, (Brasil). E-mail: solanobraga@ yahoo.com.br Orcid: https://orcid.org/00000002-6231-4756

${ }^{2}$ Universidade Federal de Juiz de Fora - UFJF, Minas Gerais, (Brasil). E-mail: guilherme.malta@gmail.com Orcid: https://orcid.org/0000-0001-8778-7763

${ }^{3}$ Universidade Federal de Minas Gerais - UFMG, Minas Gerais, (Brasil). E-mail: mvb2503@gmail.com Orcid: https://orcid.org/0000-0002-4122-7389

${ }^{4}$ Companhia de Desenvolvimento de Minas Gerais CODEMGE-MG, Minas Gerais, (Brasil). E-mail: pires_flavia@yahoo.com.br Orcid: https://orcid.org/0000-0003-1421-4512

${ }^{5}$ Universidade Federal do Piauí - UFPI, Piauí, (Brasil). E-mail: perinotto@ ufpi.edu.br Orcid: https://orcid.org/0000-0001_ 7094-3758 


\title{
ANALYSIS OF THE TOURIST ASSISTANCE CENTERS IN BELO HORIZONTE/MINAS GERAIS/BRAZIL BETWEEN 2014 AND 2018
}

\begin{abstract}
Objective of the study: This paper aims to analyze the Tourist Assistance Centers (CATs) in Belo Horizonte, Minas Gerais. By conducting a study between 2014 and 2018, we sought to understand to what extent the holding of the 2014 FIFA World Cup contributed to the improvement of tourist information services in the city.

Originality/Relevance: Tourist information has a categorical role in the promotion of a destination; as a result, the Tourist Assistance Centers takes on an important promotional role, since they concentrate information about a certain locality and about other tourist destinations in the surrounding area. The choice of the theme is justified since the improvement of the Tourist Assistance Centers was defined as one of the priority areas in the Responsibility Matrix, assumed by the municipal and state governments, besides paying attention to the importance of the quality of tourist information to have a smarter tourist destination.
\end{abstract}

Methodology/approach: This is an exploratory research, divided into two concurrent stages. In a first moment, a bibliographic survey on the theme was made and, in parallel, the structure and services provided by the CATs were evaluated through interviews and on-site evaluation, carried out in 2014, one month before the FIFA World Cup, and in May 2018. The studied items were grouped, analyzed and categorized into three topics: a) "Facilitating Product"; b) "Support Product"; and c) Extended Product.

Main results: After defining the analysis parameters and comparing the 2014 and 2018 data, it can be considered that they present a functionality that often does not fit the theory of what is meant by a CAT, as they tend to comply with function only to inform the tourist and not to captivate him/her. It was also observed that there were no improvements in the services offered by CATs after the investments made in 2014.

Theoretical/methodological contributions: (i) Conduct a theoretical review of the CATs; (ii) Propose and systematize a way of analysis and evaluation of the infrastructure and services offered; and (iii) evaluate the post2014 FIFA World Cup legacies in this area.

Keywords: TAC. Information. Tourism. FIFA 2014 World Cup. Belo Horizonte. 


\section{ANÁLISIS DE LOS CENTROS DE ATENCIÓN AL TURISTA EN BELO HORIZONTE/MINAS GERAIS/BRASIL ENTRE LOS AÑOS DE 2014 Y 2018}

\section{Resumen}

Objetivo del estudio: Este trabajo tiene como objetivo analizar los Centros de Atención al Turista (en adelante CAT) en Belo Horizonte, Minas Gerais. Al realizar un estudio entre 2014 y 2018, buscamos comprender en qué medida la realización de la Copa Mundial de la FIFA 2014 contribuyó a la mejoría de los servicios de información turística en la ciudad.

Originalidad/Relevancia: La información turística tiene un papel categórico en la promoción de un destino y, por consiguiente, los Centros de Atención al Turista asumen un importante papel de promoción, ya que concentran información sobre una determinada localidad y sobre los otros destinos turísticos al alrededor de ellos. La elección del tema está justificada ya que la mejora de los Centros de Atención al Turista fue definida como una de las áreas prioritarias en la Matriz de Responsabilidad, asumida por los gobiernos municipales y estatales, además de ofrecer atención a la importancia de la información turística de calidad para tener un destino turístico más inteligente.

Metodología/abordaje: De carácter exploratorio, la investigación fue dividida en dos etapas concomitantes: en un primer momento fue realizada la recopilación bibliográfica sobre el tema y, en paralelo, fue realizada la evaluación de la estructura y los servicios ofrecidos por los CATs, a través de entrevistas y evaluación in loco, realizadas en 2014, un mes antes del Mundial de la FIFA, y en mayo de 2018. Los elementos analizados fueron agrupados, analizados y categorizados en tres temas: a) "Producto facilitador"; b) "Producto Soporte"; y c) "Producto Ampliado".

Principales Resultados: Después de definir los parámetros de análisis y comparar los datos de 2014 y 2018, se puede considerar que presentan una funcionalidad que, muchas veces, no se ajusta a la teoría de lo que se entiende por un $C A T$, pues se espera cumplir la función solamente de informar al turista y no para cautivarlo. También fue posible observar que no hubo mejoras en los servicios ofrecidos por los CATs después de las inversiones realizadas en 2014.

Contribuciones teóricas/metodológicas: (i) Realizar una revisión teórica de los CATs; (ii) Proponer y sistematizar una forma de análisis y evaluación de la infraestructura y servicios ofrecidos; y (iii) Evaluar las contribuciones posteriores al Mundial de la FIFA 2014 en esta área.

Palabras clave: $C A T$. Información. Turismo. Mundial de la FIFA 2014. Belo Horizonte. 


\section{Introdução}

Diversos fatores têm contribuído para o aumento do fluxo turístico mundial e, consequentemente, para a valorização da experiência turística, dentre esses fatores, destaca-se: o processo de modernização, marcado pela industrialização; a globalização, que promove a integração de diversas economias e amplia a geração de negócios globais; a evolução tecnológica; além da cada vez mais crescente facilidade de mobilidade. Valendo-se do segmento de turismo esportivo, mais precisamente dos megaeventos, que serve de pano de fundo para as análises empreendidas no presente artigo, ressalta-se que na última década esse segmento foi um dos que mais cresceu em todo o mundo (Ishiy, 1998).

Em âmbito brasileiro, as recentes estatísticas publicadas pelas mais distintas entidades de pesquisa, bem como órgãos públicos e associações, reafirmam as taxas de crescimento e os resultados de movimentação econômica, como, por exemplo, a entrada de divisas. Nesse contexto, a atividade turística é percebida como importante fator estratégico de desenvolvimento econômico, que merece atenção e investimento em razão, principalmente, da sua capacidade de gerar emprego, renda e competitividade (Ferreira \& Wada, 2010; Brasil, 2010; Piscopo, 2015).

Acrescenta-se a esses benefícios a redução da sazonalidade, uma vez que o turismo corresponde a um tipo de migração temporária com transferência de renda (Oliveira, 2001) e, consequentemente, a mobilização e incentivo ao trade turístico e aos prestadores de serviço em períodos de baixa estação (Oliveira, 2001; Matias, 2007; Carneiro \& Fontes, 1997). Ademais, os eventos têm sido considerados, tanto pelo poder público quanto pela iniciativa privada, importantes estratégias de marketing (Ferreira \& Wada, 2010; Phillips Et Al., 2008; Carneiro \& Fontes, 1997), sobretudo diante do estabelecimento e fortalecimento de imagem e marca (Ferreira \& Wada, 2010; Brasil, 2009).

Frente a esse cenário, em outubro de 2007 o Brasil foi escolhido como o país-sede da Copa do Mundo FIFA 2014. Sob a responsabilidade de sediar um evento esportivo de grandes proporções, o Governo Federal elaborou um plano estratégico para que todas as cidades escolhidas tivessem condições de realizar os jogos da Copa do Mundo. Para isso, foram definidas, a partir do documento denominado Matriz de Responsabilidades (MR), sete áreas prioritárias para investimentos em infraestrutura, a saber: aeroportos, portos, mobilidade urbana, estádios, segurança, telecomunicações e turismo. A MR consistiu em um plano estratégico de investimento do país, cujas intervenções necessárias foram definidas antes da Copa do Mundo, mas viabilizadas pela realização deste evento. De acordo com o site Portal da Transparência ${ }^{6}$, o total de investimentos destinados às ações de infraestrutura do turismo para a cidade de Belo Horizonte foi da ordem de R \$ 18,54 milhões de reais.

A elaboração do presente artigo apresenta parte dos resultados referente ao projeto multidisciplinar encomendado ao Conselho Nacional de Desenvolvimento Científico e Tecnológico $-\mathrm{CNPq}^{7}$, pelo Ministério do Esporte, cuja intenção foi desenvolver pesquisas que avaliassem, sobretudo, os legados e as oportunidades gerados pela realização da Copa do Mundo FIFA 2014 em cada uma das doze cidades-sede escolhidas. Parte desse projeto foi executado pela Universidade Federal de Minas Gerais, com foco nas sete áreas prioritárias supracitadas. Os dados de 2018 foram atualizados pelos autores.

Dentro do escopo definido pela MR para Belo Horizonte encontra-se os projetos voltados para o "Desenvolvimento Turístico". É notório que os governos consideram o turismo e seu estímulo via política pública uma importante fonte de desenvolvimento econômico, sendo de máxima prioridade, sobretudo, nos países em desenvolvimento. Importante ressaltar também que o desenvolvimento econômico é, ainda hoje, dotado de considerável caráter simbólico. Por sua intrínseca relação com a noção de avanço, sobretudo econômico, a atividade turística é comumente considerada uma das estratégias possíveis para se alcançar tal resultado. Nessa perspectiva, o turismo se apresenta, predominantemente, sob o prisma do discurso governamental, como uma fonte de benefícios monetários, de geração de empregos e como um impulso para o incremento de infraestruturas que servem como apoio à sua realização.

No que tange aos projetos voltados ao turismo em Belo Horizonte no contexto pré-copa, foram requisitadas ações que compreendessem, sobretudo, acessibilidade nos atrativos turísticos; implantação,

${ }^{6}$ http://www.portaltransparencia.gov.br/copa2014/cidades/home.seam?cidadeSede=1. Acesso em: 29/04/2014 ${ }^{7}$ www.cnpq.br 
reforma e adequação de Centros de Atendimento aos Turistas (CATs); e a sinalização turística nos atrativos da cidade. $O$ total de investimentos, nessa área, de acordo com o Portal da Transparência ${ }^{8}$, foi de $\mathrm{R} \$ 8,32$ milhões de reais.

Isso posto, tendo como referências a MR e o relatório do projeto encomendado ao CNPQ, este artigo tem como principal objetivo analisar os principais resultados CATs de Belo Horizonte, principalmente no que diz respeito aos seus usos e funcionalidades, infraestrutura e investimentos destinados a estes Centros em decorrência da Copa do Mundo FIFA 2014 e durante os quatros anos posteriores ao evento. Busca-se também analisar a qualidade do atendimento oferecido, bem como a qualidade do material disponível ao turista.

\section{Revisão de Literatura}

\section{A Informação Turística e a importância dos Centros de Atendimento ao Turista}

$\mathrm{Na}$ atualidade, a atividade turística pode ser realizada de diferentes formas. Pode compreender uma ou mais localidades, apresentar motivações de viagem que variam amplamente, envolvendo atividades de negócios, recreação, lazer, esportes de aventura, dentre outros (Ruschmann, 2010). A destinação turística, da mesma forma, pode apresentar estruturas de recepção diversificadas que contam, por exemplo, com serviços de hospedagem de diferentes tipos, como restaurantes, centros de compra, entretenimento etc. Ou podem apenas oferecer uma estrutura básica que atenda às demandas de acessibilidade para que haja a visitação.

No âmbito turístico, a informação disponível tem papel categórico na promoção de um destino, na medida em que exerce grande influência na entrada de turistas, facilitando ou dificultando sua consolidação como um importante destino turístico mundial. Da mesma forma a hospitalidade da comunidade anfitriã pode ser um atrativo e ponto importante no marketing de um destino para sua promoção e característica competitiva perante outros destinos (Mendes, 2016). Entretanto, cabe aqui diferenciar o que se entende por informação e, também, diferenciá-la da comunicação. Sendo assim, "a comunicação é a ação de tornar alguma coisa comum, transmitir e receber informações. Informação, por sua vez, é o conhecimento derivado de dados, articulados entre si, para permitir uma ou mais organizações" (Brasil,

${ }^{8}$ http://www.portaltransparencia.gov.br/copa2014/cidades/tema.s eam?tema $=4 \&$ cidadeSede $=1$. Acesso em: 29/04/2014
2007, p.17). De modo complementar, pode-se considerar que "o conceito de informação estaria próximo de algo como dar forma por meio da reunião de uma série de dados. Dado é qualquer mensagem que está à disposição do utilizador, para uso oportuno" (Brasil, 2007, p.17).

Nesse sentido, segundo Bissoli (2002), os dados indicam unidades de informação, portanto, sozinhos, não possuem significado. A partir dessa diferenciação, o Ministério do Turismo define a informação como "[...] a reunião de dados que, articulados entre si e disponibilizados às pessoas e instituições, facilitarão as tomadas de decisão relacionadas ao desenvolvimento do turismo" (Brasil, 2007, p. 18).

Para Gohr et al. (2009), existem dois momentos de coleta da informação, a saber: antes da viagem, relacionada, frequentemente, à escolha do destino; e àquelas que são adquiridas já no próprio destino. Essa última se relaciona às atividades que serão realizadas no local, como a identificação dos atrativos, hospedagem, alimentação e transporte, por exemplo. Sendo assim, é importante destacar que a disponibilidade das informações está além da localidade em si e dos serviços e equipamentos turísticos locais. Da mesma forma, elas se diferenciam quanto à finalidade que possuem e, de acordo com Nascimento e Silva (2004), em qual categoria se encaixam. Na localidade visitada, a disponibilidade da informação turística de qualidade "deve ser de competência tanto do governo quanto das empresas públicas e privadas, agências de viagens, hotéis, restaurantes, polícia e bibliotecas" (Nascimento \& Silva, 2004, p. 63).

Portanto, as funções e nomenclaturas dedicadas aos espaços de recepção de turistas são variadas. Tal diversidade pode dificultar um entendimento universal de quais sejam as funções e obrigações destes espaços enquanto serviços ligados à informação turística. Assim, estes mesmos locais podem ser denominados como: Centro de Atendimento ao Turista (CAT), Ponto de Informação Turística (PIT), Centro de Informação Turística (CIT), entre outros. Ressalta-se que no caso deste relatório foi considerada a nomenclatura e a funcionalidade dos CATs.

No documento intitulado "Proposta Estratégica de Organização Turística - Copa do Mundo 2014 Brasil", elaborado pelo Ministério do Turismo e pela Fundação Getúlio Vargas, os Centros de Atendimento 
ao Turista (CATs) foram considerados locais de importância no papel promocional da cidade, pois concentram informações sobre a localidade e os demais destinos da região (Brasil, 2009). Nos CATs, em geral, "é possível receber informações e folhetaria multilíngue, além de orientação sobre movimentação, destinos do entorno, alimentação e hospedagem" (Brasil, 2009, p. 21).

Ainda segundo o referido documento, há uma diferenciação entre CAT e PIT: o primeiro é amplo, mais bem estruturado, oferece maior quantidade de serviços, além de estar localizado em postos-chave da cidade (Brasil, 2009). Dessa forma, no Centro de Atendimento ao Turista a oferta de serviços é ampliada e não fica restrita apenas à oferta da informação solicitada pelo turista. Outra razão para adotar a nomenclatura "CAT" nesse artigo foi o fato da Prefeitura Municipal de Belo Horizonte adotar esse termo para se referir aos locais destinados a disponibilizar informações aos visitantes.

Considerando que a diferenciação entre os PITs e os CATs esteja na forma como o visitante é recebido e suas dúvidas esclarecidas, se pode entender que o CAT se trata, portanto, de um centro de acolhimento e atenção ao turista. Da mesma forma, também há uma diferenciação entre os Centros de ATENDIMENTO e os Centros de INFORMAÇÃO Turística, sobretudo no que diz respeito à sua etimologia e, logo, aos seus usos e funções.

Assim, há muitas nomenclaturas e funções dadas a estes espaços. Considerando as funções atribuídas aos CATs e remetendo ao significado do verbo "atender", pode-se dizer que um Centro de Atendimento ao Turista é um local físico de acolhimento e atenção aos turistas, cujo objetivo consolida-se ao sanar suas dúvidas, assim como expandir seu conhecimento sobre a localidade e a região no intuito de promover os destinos e aumentar o tempo de permanência do visitante.

Filho (2005) destaca que as pesquisas sobre os CATs no Brasil são ainda incipientes, existindo apenas algumas contribuições em livros introdutórios ou que tratam do assunto de forma superficial, como as obras de Barreto (1997), Ignarra (1999) e Beni (2001). Os poucos estudos encontrados sobre o tema são, em grande parte, estrangeiros e possuem como temas principais: a utilização de centros de informação por turistas de diferentes origens; o papel que os centros de informações turísticas têm no retorno de turistas para a localidade; o impacto dos gastos dos turistas após passarem por centros de informações turísticas; a busca de informações por possíveis turistas em centros de informações turísticas (virtuais); as tecnologias utilizadas em centros de informações turísticas; a força de trabalho utilizada em centros de informações turísticas; a efetividade, qualidade do conteúdo, reservas on-line e "desintermediação" em centros de informações turísticas virtuais (Filho, 2005).

A referência mais antiga utilizada, ainda de acordo com Filho (2005), foi Füster (1985), que considerava que um CIT deveria ter recepção, sala de reuniões/exposições, escritório para atividades internas, arquivo, sanitários e serviços de informação. Em uma situação ideal, Füster (1985) acreditava que os CATs (ou CIT, como usado pelo autor em questão) deveriam possuir no setor de atenção ao público: vestiários, sanitários, salas, balcões, serviços de informática, setor de escritórios para as atividades administrativas e informativas por telefone, fax, telex, sistemas de informação, vídeo etc., arquivo de material de propaganda, arquivo geral, banco e base de dados informatizados. Notadamente, Füster (1985) dava mais destaque aos aspectos físicos dos CATs. Assim, suas considerações serão levadas em conta na avaliação dos aspectos físicos dos centros de atendimentos ao turista que será realizada posteriormente.

Já Castelli (2001) destaca a importância de se ter informações disponíveis e atualizadas, além de atendentes preparados para atender bem ao turista. Para esse autor, as informações e os recursos humanos são as principais matérias primas para o bom funcionamento dos CATs, para ele, de nada adianta construir um excelente CAT e equipá-lo de aparelhamentos, instalações e informações se o fator humano que desempenha as funções não estiver preparado.

Ainda, importante ressaltar que as funções de um CAT podem variar bastante, dependendo de seu objetivo, localização, porte, estruturação e gestão. Para Filho (2005), os CATs devem cumprir as seguintes funções: fornecer informações turísticas; prestar serviços de agências de viagens (reservas de serviços em estabelecimentos turísticos - meios de hospedagem, traslados, guias de turismo, reservas em shows e outros eventos, dicas de atrativos turísticos etc.); disponibilizar banheiros; disponibilizar serviços de alimentação (restaurantes, lanchonetes e lojas de conveniência); entre outras.

Pearce (1991), Moscardo (1998, 1999) identificaram quatro funções dos CATs: Marketing e acesso - promover uma área e seus produtos; fornecer informação, sugerir produtos turísticos, sugestões de onde ficar e do que fazer, como chegar; - Aprimorar e informar - aumentar a qualidade da estadia do 
visitante, fornecendo informações mais profundas; Controle e filtragem - busca reduzir os gastos desnecessários dos turistas e ajuda a informar o que ele não quer ver. Por exemplo, se o turista deseja permanecer mais tempo em determinado atrativo turístico, deve-se informar as opções de hospedagem e alimentação nas imediações. Ou ainda, se existe alguma região em que os índices de violência estejam altos, deve-se informar ao turista, e; Substituição sugerir locais que não sejam indicados para que o turista visite - aconselhando a troca de atrativos em casos específicos.

De acordo com Füster (1985), a gestão administrativa nos CATs é determinada para as seguintes funções: administrar o financiamento das infraestruturas e serviços (formas de financiamento próprias ou externas); relação com outras atividades e empresas turísticas; preparação de informativos; tratamento administrativo de reclamações e queixas; tratamento administrativo de vistos e divisas; controle de estatísticas; gestão de pessoal: planejamento, organização, direção, motivação; controle econômico: controle de orçamento e análise e controle de custos dos serviços informativos; controle de qualidade dos serviços de informação turística; legislação geral e turística: autonômicas, estatais e comunitárias.

Como afirmam Espigão et al. (2012), os CATs têm ainda como responsabilidade influenciar positivamente na tomada de decisão do turista em relação à seleção dos serviços oferecidos no destino visitado, assim como determinar a qualidade dos mesmos e, consequentemente, sua satisfação com relação à localidade. Ainda, o CAT deve oferecer informações multilíngues em meio impresso e digital com veracidade e clareza. $\mathrm{O}$ ambiente deve oferecer comodidade, segurança e conforto, pois auxilia "o turista a estabelecer a primeira impressão de uma localidade" (Filho, 2005, p. 53).

Nesse cenário, cumpre apontar que um dos pontos fundamentais para a efetivação dos CATs como locais de apoio e influência na permanência do visitante no local, é a capacitação dos elementos humanos que realizam o atendimento direto com o público.
Segundo Castelli (2001), os centros não devem ficar desprovidos de informação, desatualizados e sem pessoal capacitado. Dessa forma, esses espaços devem atuar como um agente indutor da permanência e qualidade da experiência do turista na localidade ou no entorno. A qualidade do atendimento ao turista e a adequada infraestrutura dos CATs, com equipamentos e instalações apropriadas tornam-se, portanto, elementos primordiais para a execução de sua função.

\section{Metodologia}

Com o intuito de atender aos objetivos propostos, a pesquisa foi dividida em diferentes etapas, de distintas naturezas metodológicas.

$\mathrm{Na}$ busca de entender e caracterizar conceitual e empiricamente os CATs foram realizadas pesquisas bibliográficas envolvendo o tema da informação turística, bem como sobre o tema específico dos CATs. Tais pesquisas tiveram como intuito introduzir os temas discutidos e debater acerca de sua importância no contexto turístico atual e suas especificidades. Paralelamente, foram feitas avaliações referentes à estrutura e aos serviços prestados pelos centros, por meio de entrevistas e avaliação in loco das estruturas. As visitas foram feitas em junho de 2014, um mês antes da realização da Copa do Mundo FIFA e em maio de 2018. Ao todo, foram avaliados sete CATs, a saber: Mercado Central, Mercado das Flores, Rodoviária, Praça da Liberdade, Aeroportos de Confins e Pampulha, CAT Álvaro Hardy, conhecido como "Veveco" (localizado nas proximidades da Casa do Baile, na região da Pampulha).

Entendendo a importância dos aspectos físicos, a disponibilidade de informações e a qualidade de atendimento, e tendo como base os investimentos realizados pelo poder público relacionado à realização da Copa do Mundo FIFA 2014, os CATs de Belo Horizonte foram aqui avaliados com base em suas estruturas e no que diz respeito à sensação de bemestar que o espaço oferece aos usuários. Assim, os itens citados no quadro abaixo serviram de referência para avaliação dos CATs em Belo Horizonte: 
Figura 1: Variáveis de avaliação da estrutura de um Centro de informação turística - CIT e sua composição

\begin{tabular}{|c|c|}
\hline \multicolumn{2}{|c|}{ Variáveis de avaliação da estrutura de um CIT e sua composição } \\
\hline \multicolumn{2}{|c|}{ PRODUTO ESSENCIAL - corresponde às expectativas básicas do turista ao receber a informação. } \\
\hline & COMPOSIÇÃO \\
\hline $\begin{array}{l}\text { PRODUTO FACILITADOR } \\
\text { Representa o material necessário } \\
\text { para tornar possível o produto } \\
\text { essencial. }\end{array}$ & $\begin{array}{l}\text { Mapas e folders (informaçães): agências de viagens; meios de } \\
\text { hospedagens; locadoras de veículos; lojas de conveniência; lojas de } \\
\text { souvenirs; serviços de alimentação; câmbio; meios de transportes; } \\
\text { telefones úteis; horário de funcionamento de atrativos; calendário de } \\
\text { eventos }\end{array}$ \\
\hline $\begin{array}{l}\text { PRODUTO DE SUPORTE } \\
\text { É o que acrescenta valor ao } \\
\text { produto essencial, diferenciando- } \\
\text { o de outros serviços. }\end{array}$ & $\begin{array}{l}\text { Serviços de reservas (meios de hospedagem; serviços de alimentação; } \\
\text { locação de veículos; city tour), informação em língua estrangeira,venda de } \\
\text { souvenirs, loja de conveniência, venda de tickets (eventos/entretenimento; } \\
\text { transportes; atrativos turísticos), disponibilização de acesso à internet, } \\
\text { vídeos ilustrativos, previsão do tempo, dicas úteis, sites e fotos llustrativas }\end{array}$ \\
\hline \multicolumn{2}{|c|}{ PRODUTO AMPLIADO - é a junção do produto essencial, facilitador e de suporte com quatro elementos básicos: } \\
\hline Acessibilidade & $\begin{array}{l}\text { Localização física; facilidade de localização visual, acessibilidade para } \\
\text { deficientes físico/visual, horários de funcionamento e vias de acesso }\end{array}$ \\
\hline Atmosfera & $\begin{array}{l}\text { Aparência física condizente com o destino (ambiente hospitaleiro), guichê, } \\
\text { tamanho, sons e banheiros }\end{array}$ \\
\hline $\begin{array}{l}\text { Participação dos clientes com o } \\
\text { CIT }\end{array}$ & Atendentes com pelo menos o 20 idioma, email e redes sociais \\
\hline Interação dos clientes entre si & Espaço que proporcione interação entre os clientes \\
\hline \multicolumn{2}{|c|}{$\begin{array}{l}\text { Fonte: elaboração própria a partir da leitura de Kotler, P., Bowen J. \& Makens, J. Marketing for Hospitality and } \\
\text { Tourism. Second EdiUSA: Prentice Hall, 1999, pp. 274-283. }\end{array}$} \\
\hline
\end{tabular}

Fonte: Espigão et al. (2012).

Assim, de modo geral, quatro elementos de avaliação foram utilizados: comodidade, acessibilidade, segurança e refrigeração. Ressalta-se, todavia, que a análise não teve como foco a avaliação das estruturas físicas propriamente ditas, mas sim, a percepção dos usuários ao frequentar esses espaços. Os itens analisados foram agrupados, analisados e categorizados em três tópicos:

a) "Produto Facilitador" (1- Mapas e Folders; 2 Agências de viagens; meios de hospedagem; locadoras de veículos; lojas de conveniência; lojas de souvenirs; serviços de alimentação; câmbio; 3 - Meios de transporte; 4 - Telefones úteis, 5 - Horário de funcionamento de atrativos e, 6 - Calendário de eventos);

b) "Produto Suporte" (1 - Serviços de reservas (meios de hospedagem; serviços de alimentação; locação de veículos; city tour); 2 - Informação em língua estrangeira; 3 - Venda de souvenirs; lojas de conveniência; venda de tickets (eventos, entretenimento, transportes) e, 4 - Disponibilização de acesso à internet, vídeos ilustrativos; previsão do tempo; dicas úteis; sites e fotos ilustrativas); e

c) "Produto Ampliado" (1 - Acessibilidade: Localização física; facilidade de localização físico/visual; horários de funcionamento e vias de acesso; 2 - Atmosfera: Aparência física condizente com o destino (ambiente hospitaleiro), guichê, tamanho, sons e banheiro; 3 - Participação dos clientes com a CAT: Atendentes com pelo menos $2^{\circ}$ idioma, email e redes sociais, e 4 - Interação dos clientes entre si: Espaço que proporcione interação entre os usuários.) A classificação teve como embasamento a revisão bibliográfica citada e consistiu em avaliar a estrutura, materiais de informação turística e serviços disponíveis para o turista que visita o CAT em "Atende" (quando existe a disponibilidade e qualidade do serviço/estrutura/informação analisado), "Atende Parcialmente" (quando existe a disponibilidade, mas a qualidade do serviço/estrutura/informação analisado não atendeu ao padrão descrito na revisão bibliográfica) e "Não atende" (quando não existe a disponibilidade do serviço/estrutura/informação analisado).

Além da pesquisa bibliográfica e documental dos temas acima citados e como forma de complementar a análise dos CATs, foram realizadas, também, algumas entrevistas com representantes dos principais órgãos públicos de turismo de Belo Horizonte e do Estado de Minas Gerais, além das entrevistas com os funcionários dos CATs. Para conhecer as percepções dos atendentes dos CATs de Belo Horizonte, realizaram-se sete entrevistas semiestruturadas de caráter qualitativo, com agendamentos prévios. As entrevistas seguiram um roteiro composto por vinte perguntas e foram realizadas de forma presencial e telefone.

\section{Cats de Belo Horizonte}

\section{Centros de Atendimento ao Turista de Belo Horizonte}

Os Centros de Atendimento ao Turista presentes em Belo Horizonte são de responsabilidade e gestão da Empresa Municipal de Turismo de Belo Horizonte S.A. 
Análise dos Centros de Atendimento ao Turista em Belo Horizonte/Minas Gerais/Brasil entre os Anos de 2014 e 2018

(BELOTUR), com exceção do CAT localizado no Mercado Central $^{9}$, gerido pela administração do próprio Mercado. São sete centros dispostos em locais de grande fluxo turístico da capital (MAPA 1), sendo eles: Mercado Central, Mercado das Flores, Rodoviária, Praça da
Liberdade, Aeroportos de Confins e Pampulha, além do CAT Álvaro Hardy, conhecido como "Veveco" (localizado nas proximidades da Casa do Baile, na região da Pampulha).

Mapa 1: Localização dos CATs

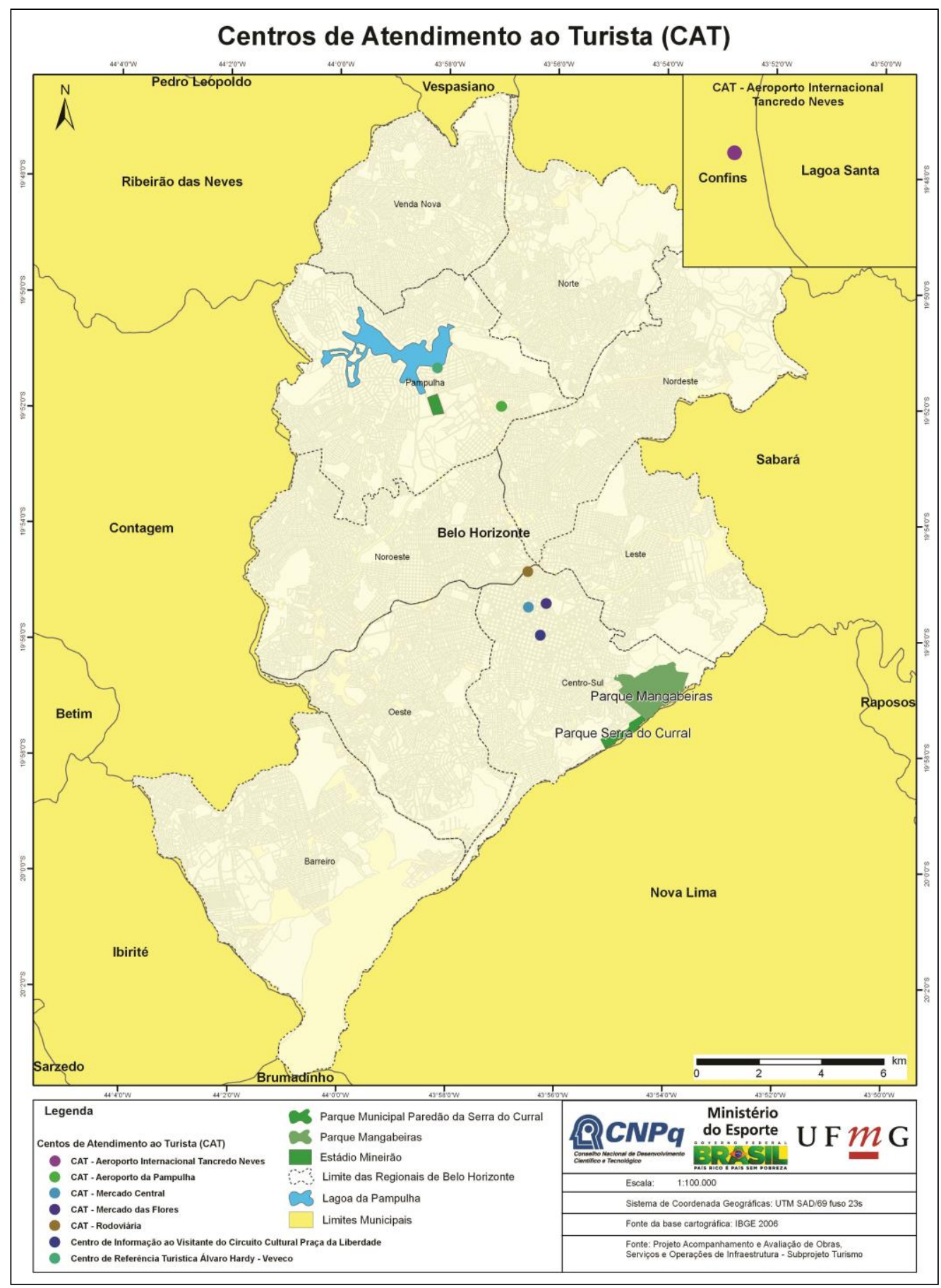

Fonte: UFMG, 2014

\footnotetext{
${ }^{9}$ Para maiores informações acessar Mercado Central. Disponível
} em: http://www.mercadocentral.com.br/ Acesso: 29/07/2014 
Os CATs dispõem de materiais impressos como folhetos, guias e mapas de Belo Horizonte e de destinos turísticos mineiros de grande expressão nacional, como a cidade de Ouro Preto, por exemplo. O horário de funcionamento dos CATs é, em geral, de $8 \mathrm{~h} 00$ às $18 \mathrm{~h} 00$, variando nos finais de semana. Os funcionários que trabalham no atendimento dos CATs são contratados pela Prefeitura Municipal de Belo Horizonte ou são estagiários, geralmente de cursos de turismo das universidades e faculdades de Belo Horizonte. Ainda, os CATs dispõem de infraestruturas físicas diferenciadas, dependendo do local em que estão dispostos. É possível observar no mapa a seguir que a maioria dos CATs está concentrada Região Centro-Sul de Belo Horizonte.

\section{Centro de Referência Turística Álvaro Hardy - Veveco}

O CAT Álvaro Hardy, mais conhecido como "Veveco", diferencia-se dos outros CATs da cidade, pois é considerado pela prefeitura Como um "Centro de Referência Turística". No entanto, não foi identificado nenhum diferencial no atendimento se comparado aos outros CATs analisados e sua atividade se restringe às de um posto de informação turística e distribuição de material promocional da cidade de Belo Horizonte.

Este CAT conta com um espaço amplo e cômodo para o atendimento ao turista, apesar de não oferecer banheiros aos visitantes. Encontra-se na orla da Lagoa da Pampulha, próximo ao atrativo turístico arquitetônico Casa do Baile. Vale dizer que essa região é considerada um dos polos turísticos mais importantes da cidade de Belo Horizonte e recentemente recebeu a chancela da UNESCO como Patrimônio da Humanidade ${ }^{10}$. Abaixo, segue o quadro síntese de avaliação da estrutura padrão para todos os CATs tendo como eixos os itens da revisão teórica e agrupados entre "Produto facilitador", "Produto Suporte" e "Produto Ampliado":

Quadro 1: Avaliação do CAT Veveco

\begin{tabular}{|c|c|c|}
\hline Descrição & Avaliação*- 2014 & Avaliação - 2018 \\
\hline \multicolumn{3}{|l|}{ Produto Facilitador } \\
\hline Mapas e Folders & Atende & Atende \\
\hline $\begin{array}{l}\text { Agências de viagens; meios de hospedagem; locadoras de veículos; lojas } \\
\text { de conveniência; lojas de souvenirs; serviços de alimentação; câmbio; }\end{array}$ & Atende & Atende \\
\hline Meios de transporte & Atende & Atende \\
\hline Telefones úteis & Atende & Atende \\
\hline Horário de funcionamento de atrativos & Atende & Atende \\
\hline Calendário de eventos & Atende & Atende \\
\hline \multicolumn{3}{|l|}{ Produto Suporte } \\
\hline $\begin{array}{l}\text { Serviços de reservas (meios de hospedagem; serviços de alimentação; } \\
\text { locação de veículos; city tour) }\end{array}$ & Não atende & $\begin{array}{l}\text { Atende } \\
\text { parcialmente }\end{array}$ \\
\hline Informação em língua estrangeira & Não atende & Atende \\
\hline $\begin{array}{l}\text { Venda de souvenirs; lojas de conveniência; venda de tickets (eventos, } \\
\text { entretenimento, transportes) }\end{array}$ & Não atende & $\begin{array}{l}\text { Atende } \\
\text { parcialmente }\end{array}$ \\
\hline $\begin{array}{l}\text { Disponibilização de acesso à internet, vídeos ilustrativos; previsão do } \\
\text { tempo; dicas úteis; sites e fotos ilustrativas }\end{array}$ & Não atende & $\begin{array}{l}\text { Atende } \\
\text { parcialmente }\end{array}$ \\
\hline \multicolumn{3}{|l|}{ Produto Ampliado } \\
\hline $\begin{array}{l}\text { Acessibilidade: Localização física; facilidade de localização } \\
\text { físico/visual; horários de funcionamento e vias de acesso. }\end{array}$ & Atende & Atende \\
\hline $\begin{array}{l}\text { Atmosfera: Aparência física condizente com o destino (ambiente } \\
\text { hospitaleiro), guichê, tamanho, sons e banheiro }\end{array}$ & $\begin{array}{l}\text { Atende } \\
\text { parcialmente }\end{array}$ & Atende \\
\hline $\begin{array}{l}\text { Participação dos clientes com a CAT: Atendentes com pelo menos } 2^{\circ} \\
\text { idioma, e-mail e redes sociais. }\end{array}$ & Atende & Atende \\
\hline $\begin{array}{l}\text { Interação dos clientes entre si: Espaço que proporcione interação entre os } \\
\text { usuários. }\end{array}$ & Atende & Atende \\
\hline
\end{tabular}

* Disponibilidade / qualidade

Fonte da base de dados: UFMG, 2014 e levantamento realizado pelos autores em 2018.

${ }^{10} \mathrm{http}: / /$ www.unesco.org/new/pt/brasilia/culture/worldheritage/list-of-world-heritage-in-brazil/pampulha-modernensemble/ Acessado: 19/05/2018. 


\section{Centro de Atendimento ao Turista (CAT) - Mercado das Flores}

O CAT Mercado das Flores oferece espaço interno aos visitantes, já que conta com alguns assentos e uma televisão. Assim como o "Veveco", também não há banheiros no interior desse Centro para uso dos visitantes, todavia, há banheiros disponíveis, cujo acesso se dá pelo Parque Municipal Renné Gianetti, localizado ao lado do CAT. Além das atividades de posto de informações turísticas e distribuição de material promocional da cidade de Belo Horizonte, no local também são vendidos ingressos para eventos que acontecem exclusivamente na cidade, e que são apoiados pela BELOTUR, como, por exemplo, a Campanha de Popularização do Teatro e da Dança. Abaixo, segue o quadro síntese de avaliação da estrutura do referido CAT:

Quadro 2: Avaliação do CAT Mercado das Borboletas

\begin{tabular}{|c|c|c|}
\hline Descrição & Avaliação* - 2014 & Avaliação-2018 \\
\hline \multicolumn{3}{|l|}{ Produto Facilitador } \\
\hline Mapas e Folders & Atende & Fechado \\
\hline $\begin{array}{l}\text { Agências de viagens; meios de hospedagem; locadoras de veículos; lojas de } \\
\text { conveniência; lojas de souvenirs; serviços de alimentação; câmbio; }\end{array}$ & Atende & Fechado \\
\hline Meios de transporte & Atende & Fechado \\
\hline Telefones úteis & Atende & Fechado \\
\hline Horário de funcionamento de atrativos & Atende & Fechado \\
\hline Calendário de eventos & Atende & Fechado \\
\hline \multicolumn{3}{|l|}{ Produto Suporte } \\
\hline $\begin{array}{l}\text { Serviços de reservas (meios de hospedagem; serviços de alimentação; } \\
\text { locação de veículos; city tour) }\end{array}$ & Não atende & Fechado \\
\hline Informação em língua estrangeira & Não atende & Fechado \\
\hline $\begin{array}{l}\text { Venda de souvenirs; lojas de conveniência; venda de tickets (eventos, } \\
\text { entretenimento, transportes) }\end{array}$ & $\begin{array}{l}\text { Atende } \\
\text { parcialmente }\end{array}$ & Fechado \\
\hline $\begin{array}{l}\text { Disponibilização de acesso à internet, vídeos ilustrativos; previsão do } \\
\text { tempo; dicas úteis; sites e fotos ilustrativas }\end{array}$ & Não atende & Fechado \\
\hline \multicolumn{3}{|l|}{$\begin{array}{ll}\text { Produto Ampliado } & \text { Am } \\
\end{array}$} \\
\hline $\begin{array}{l}\text { Acessibilidade: Localização física; facilidade de localização físico/visual; } \\
\text { horários de funcionamento e vias de acesso. }\end{array}$ & Atende & Fechado \\
\hline $\begin{array}{l}\text { Atmosfera: Aparência física condizente com o destino (ambiente } \\
\text { hospitaleiro), guichê, tamanho, sons e banheiro }\end{array}$ & $\begin{array}{l}\text { Atende } \\
\text { parcialmente }\end{array}$ & Fechado \\
\hline Participação dos clientes: Atendentes com $2^{\circ}$ idioma, e-mail e redes sociais. & Atende & Fechado \\
\hline $\begin{array}{l}\text { Interação dos clientes entre si: Espaço que proporcione interação entre os } \\
\text { usuários. }\end{array}$ & Atende & Fechado \\
\hline
\end{tabular}

Cumpre ressaltar que os dados não puderam ser atualizados, pois o CAT está fechado desde agosto de 2017. A previsão era que o mesmo seria reaberto em dezembro do mesmo ano ${ }^{11}$, mas permanece fechado até a presente data, maio de 2018.

\section{Centro de Informação ao Visitante do Circuito Cultural Praça da Liberdade}

Inicialmente instalado no "Prédio Verde", antiga sede da Secretaria de Estado de Transportes e Obras
Públicas, em 2014, o CAT conta com atendentes multilíngues em inglês, espanhol, francês e Italiano, além de intérpretes em Linguagem Brasileira de Sinais (Libras) e Braille. Atualmente o CAT está no prédio "Rainha da Sucata", também na Praça da Liberdade.

No local, o turista pode se informar sobre as principais atrações de cada espaço, bem como orientações sobre outros pontos turísticos de Belo Horizonte. Além do atendimento interpessoal, o

\footnotetext{
${ }^{11}$ http://hojeemdia.com.br/horizontes/em-reforma-desde-agostomercado-das-flores-deve-voltar-a-funcionar-at\%C3\%A9-o-fimde-2017-1.567669/cat-mercado-das-flores-1.567671.
} 
Centro conta com totens que detalham desde serviços de alimentação e transporte mais próximos até roteiros de visitação conforme a necessidade de visitante (roteiros para um dia, para o público infantil, para estudantes, entre outros). Abaixo segue o quadro síntese de avaliação da estrutura do referido centro:

Quadro 3: Avaliação do CAT Praça da Liberdade

\begin{tabular}{|c|c|c|}
\hline Descrição & 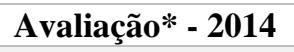 & Avaliação - 2018 \\
\hline \multicolumn{3}{|l|}{ Produto Facilitador } \\
\hline Mapas e Folders & Atende & Atende \\
\hline $\begin{array}{l}\text { Agências de viagens; meios de hospedagem; locadoras de veículos; lojas } \\
\text { de conveniência; lojas de souvenirs; serviços de alimentação; câmbio; }\end{array}$ & Atende & Atende \\
\hline Meios de transporte & Atende & Atende \\
\hline Telefones úteis & Atende & Não atende \\
\hline Horário de funcionamento de atrativos & Atende & Atende \\
\hline Calendário de eventos & Atende & Atende \\
\hline \multicolumn{3}{|l|}{ Produto Suporte } \\
\hline $\begin{array}{l}\text { Serviços de reservas (meios de hospedagem; serviços de alimentação; } \\
\text { locação de veículos; city tour) }\end{array}$ & Não atende & Não atende \\
\hline Informação em língua estrangeira & Não atende & Atende \\
\hline $\begin{array}{l}\text { Venda de souvenirs; lojas de conveniência; venda de tickets (eventos, } \\
\text { entretenimento, transportes) }\end{array}$ & Não atende & Atende \\
\hline $\begin{array}{l}\text { Disponibilização de acesso à internet, vídeos ilustrativos; previsão do } \\
\text { tempo; dicas úteis; sites e fotos ilustrativas }\end{array}$ & Não atende & $\begin{array}{l}\text { Atende } \\
\text { parcialmente }\end{array}$ \\
\hline \multicolumn{3}{|l|}{ Produto Ampliado } \\
\hline $\begin{array}{l}\text { Acessibilidade: Localização física; facilidade de localização } \\
\text { físico/visual; horários de funcionamento e vias de acesso. }\end{array}$ & Atende & Atende \\
\hline $\begin{array}{l}\text { Atmosfera: Aparência física condizente com o destino (ambiente } \\
\text { hospitaleiro), guichê, tamanho, sons e banheiro }\end{array}$ & $\begin{array}{l}\text { Atende } \\
\text { parcialmente }\end{array}$ & Atende \\
\hline $\begin{array}{l}\text { Participação dos clientes: Atendentes com } 2^{\circ} \text { idioma, e-mail e redes } \\
\text { sociais. }\end{array}$ & Atende & Atende \\
\hline $\begin{array}{l}\text { Interação dos clientes entre si: Espaço que proporcione interação entre os } \\
\text { usuários. }\end{array}$ & Atende & Atende \\
\hline
\end{tabular}

Esse foi um dos únicos CATs em que foi observada a melhoria da infraestrutura e atendimento no comparativo $2014-2018$.

A mudança de endereço para outro espaço na Praça de Liberdade que foi reformado para receber o CAT, segundo os dados observados em campo, possibilitou a melhoria apresentada no quadro.

\section{Centro de Atendimento ao Turista (CAT) - Mercado Central}

O CAT do Mercado Central funciona em um quiosque em uma das entradas do Mercado. Sua função principal é a distribuição de material informativo e promocional. Abaixo segue o quadro síntese de avaliação de sua estrutura:

Quadro 4: Avaliação do CAT Mercado Central

\begin{tabular}{|c|c|c|}
\hline Descrição & Avaliação* - 2014 & Avaliação - 2018 \\
\hline \multicolumn{3}{|l|}{ Produto Facilitador } \\
\hline Mapas e Folders & Atende & Atende \\
\hline $\begin{array}{l}\text { Agências de viagens; meios de hospedagem; locadoras de veículos; lojas } \\
\text { de conveniência; lojas de souvenirs; serviços de alimentação; câmbio; }\end{array}$ & Atende & Atende \\
\hline Meios de transporte & Atende & Atende \\
\hline Telefones úteis & Atende & Atende \\
\hline Horário de funcionamento de atrativos & Atende & Atende \\
\hline Calendário de eventos & Atende & Atende \\
\hline \multicolumn{3}{|l|}{ Produto Suporte } \\
\hline
\end{tabular}


Serviços de reservas (meios de hospedagem; serviços de alimentação; Não atende locação de veículos; city tour)

Informação em língua estrangeira

Não atende

Venda de souvenirs; lojas de conveniência; venda de tickets (eventos, Não atende entretenimento, transportes)

Disponibilização de acesso à internet, vídeos ilustrativos; previsão do Não atende tempo; dicas úteis; sites e fotos ilustrativas

\section{Produto Ampliado}

Acessibilidade: Localização física; facilidade de localização físico/visual; horários de funcionamento e vias de acesso.

Atmosfera: Aparência física condizente com o destino (ambiente hospitaleiro), guichê, tamanho, sons e banheiro

Participação dos clientes: Atendentes com $2^{\circ}$ idioma, e-mail e redes sociais.

Interação dos clientes entre si: Espaço que proporcione interação entre os Não atende

\section{Atende parcialmente}

Atende parcialmente

Atende usuários.

* Disponibilidade / qualidade

Fonte da base de dados: UFMG, 2014 e levantamento realizado pelos autores em 2018
Centro de Atendimento ao Turista (CAT) Aeroporto da Pampulha

O CAT do Aeroporto da Pampulha funciona em um espaço limitado e sua função principal é a distribuição de material informativo e promocional. A única mudança com relação ao ano de 2018 , foi sua localização, que agora está mais próximo à área de desembargue o que facilitou o acesso para os passageiros. Abaixo segue o quadro síntese de avaliação da estrutura do referido CAT:

Quadro 5: Avaliação do CAT Aeroporto da Pampulha

\begin{tabular}{|c|c|c|}
\hline Descrição & Avaliação* - 2014 & Avaliação - 2018 \\
\hline \multicolumn{3}{|l|}{ Produto Facilitador } \\
\hline Mapas e Folders & Atende & Atende \\
\hline $\begin{array}{l}\text { Agências de viagens; meios de hospedagem; locadoras de veículos; lojas } \\
\text { de conveniência; lojas de souvenirs; serviços de alimentação; câmbio; }\end{array}$ & Atende & Atende \\
\hline Meios de transporte & Atende & Atende \\
\hline Telefones úteis & Atende & Atende \\
\hline Horário de funcionamento de atrativos & Atende & Atende \\
\hline Calendário de eventos & Atende & Atende \\
\hline \multicolumn{3}{|l|}{ Produto Suporte } \\
\hline $\begin{array}{l}\text { Serviços de reservas (meios de hospedagem; serviços de alimentação; } \\
\text { locação de veículos; city tour) }\end{array}$ & Não atende & Não atende \\
\hline Informação em língua estrangeira & Não atende & Não atende \\
\hline $\begin{array}{l}\text { Venda de souvenirs; lojas de conveniência; venda de tickets (eventos, } \\
\text { entretenimento, transportes) }\end{array}$ & Não atende & Não atende \\
\hline $\begin{array}{l}\text { Disponibilização de acesso à internet, vídeos ilustrativos; previsão do } \\
\text { tempo; dicas úteis; sites e fotos ilustrativas }\end{array}$ & Não atende & Não atende \\
\hline \multicolumn{3}{|l|}{ Produto Ampliado } \\
\hline $\begin{array}{l}\text { Acessibilidade: Localização física; facilidade de localização físico/visual; } \\
\text { horários de funcionamento e vias de acesso. }\end{array}$ & Não atende & Atende \\
\hline $\begin{array}{l}\text { Atmosfera: Aparência física condizente com o destino (ambiente } \\
\text { hospitaleiro), guichê, tamanho, sons e banheiro }\end{array}$ & Não atende & $\begin{array}{l}\text { Atende } \\
\text { parcialmente }\end{array}$ \\
\hline $\begin{array}{l}\text { Participação dos clientes: Atendentes com } 2^{\circ} \text { idioma, e-mail e redes } \\
\text { sociais. }\end{array}$ & Atende & Atende \\
\hline $\begin{array}{l}\text { Interação dos clientes entre si: Espaço que proporcione interação entre os } \\
\text { usuários. }\end{array}$ & Não atende & Atende \\
\hline
\end{tabular}


Centro de Atendimento ao Turista (CAT) Aeroporto Internacional Tancredo Neves

O CAT de Confins foi inaugurado para a Copa do Mundo 2014. Diferente do que acontecia anteriormente, buscou-se padronizar o quiosque e se preocupar com a acessibilidade. Não houve alterações no CAT entre 2014 e 2018. Abaixo segue o quadro síntese de avaliação de sua estrutura:

Quadro 6: Avaliação do CAT Confins

\begin{tabular}{|c|c|c|}
\hline Descrição & Avaliação* - 2014 & Avaliação - 2018 \\
\hline \multicolumn{3}{|l|}{ Produto Facilitador } \\
\hline Mapas e Folders & Atende & Atende \\
\hline $\begin{array}{l}\text { Agências de viagens; meios de hospedagem; locadoras de veículos; lojas } \\
\text { de conveniência; lojas de souvenirs; serviços de alimentação; câmbio; }\end{array}$ & Atende & Atende \\
\hline Meios de transporte & Atende & Atende \\
\hline Telefones úteis & Atende & Atende \\
\hline Horário de funcionamento de atrativos & Atende & Atende \\
\hline Calendário de eventos & Atende & Atende \\
\hline \multicolumn{3}{|l|}{ Produto Suporte } \\
\hline $\begin{array}{l}\text { Serviços de reservas (meios de hospedagem; serviços de alimentação; } \\
\text { locação de veículos; city tour) }\end{array}$ & Não atende & Não atende \\
\hline Informação em língua estrangeira & Não atende & Não atende \\
\hline $\begin{array}{l}\text { Venda de souvenirs; lojas de conveniência; venda de tickets (eventos, } \\
\text { entretenimento, transportes) }\end{array}$ & Não atende & Não atende \\
\hline $\begin{array}{l}\text { Disponibilização de acesso à internet, vídeos ilustrativos; previsão do } \\
\text { tempo; dicas úteis; sites e fotos ilustrativas }\end{array}$ & $\begin{array}{l}\text { Atende } \\
\text { parcialmente }\end{array}$ & $\begin{array}{l}\text { Atende } \\
\text { parcialmente }\end{array}$ \\
\hline \multicolumn{3}{|c|}{ Produto Ampliado } \\
\hline $\begin{array}{l}\text { Acessibilidade: Localização física; facilidade de localização } \\
\text { físico/visual; horários de funcionamento e vias de acesso. }\end{array}$ & Atende & Atende \\
\hline $\begin{array}{l}\text { Atmosfera: Aparência física condizente com o destino (ambiente } \\
\text { hospitaleiro), guichê, tamanho, sons e banheiro }\end{array}$ & Atende & Atende \\
\hline $\begin{array}{l}\text { Participação dos clientes: Atendentes com } 2^{\circ} \text { idioma, e-mail e redes } \\
\text { sociais. }\end{array}$ & Atende & Atende \\
\hline $\begin{array}{l}\text { Interação dos clientes entre si: Espaço que proporcione interação entre os } \\
\text { usuários. }\end{array}$ & Atende & Atende \\
\hline
\end{tabular}

\section{Centro de Atendimento ao Turista (CAT) - Rodoviária}

O novo balcão de informações do CAT Rodoviária está localizado no primeiro saguão de entrada do edifício. Apresenta estrutura ampla e balcão de atendimento mais baixo que os demais CATs de Belo Horizonte, com o intuito de facilitar o acesso a cadeirantes. Abaixo segue o quadro síntese de avaliação da estrutura do CAT:

Quadro 7: Avaliação do CAT Rodoviária

\begin{tabular}{|c|c|c|}
\hline Descrição & Avaliação* - 2014 & Avaliação - 2018 \\
\hline \multicolumn{3}{|l|}{ Produto Facilitador } \\
\hline Mapas e Folders & Atende & Atende \\
\hline $\begin{array}{l}\text { Agências de viagens; meios de hospedagem; locadoras de veículos; lojas } \\
\text { de conveniência; lojas de souvenirs; serviços de alimentação; câmbio; }\end{array}$ & Atende & $\begin{array}{l}\text { Atende } \\
\text { parcialmente }\end{array}$ \\
\hline Meios de transporte & Atende & Atende \\
\hline Telefones úteis & Atende & Atende \\
\hline Horário de funcionamento de atrativos & Atende & Atende \\
\hline Calendário de eventos & Atende & Atende \\
\hline
\end{tabular}




\begin{tabular}{|c|c|c|}
\hline \multicolumn{3}{|l|}{ Produto Suporte } \\
\hline $\begin{array}{l}\text { Serviços de reservas (meios de hospedagem; serviços de alimentação; } \\
\text { locação de veículos; city tour) }\end{array}$ & Não atende & Não atende \\
\hline Informação em língua estrangeira & Não atende & $\begin{array}{l}\text { Atende } \\
\text { parcialmente }\end{array}$ \\
\hline $\begin{array}{l}\text { Venda de souvenirs; lojas de conveniência; venda de tickets (eventos, } \\
\text { entretenimento, transportes) }\end{array}$ & Não atende & Não atende \\
\hline $\begin{array}{l}\text { Disponibilização de acesso à internet, vídeos ilustrativos; previsão do } \\
\text { tempo; dicas úteis; sites e fotos ilustrativas }\end{array}$ & Não atende & Não atende \\
\hline \multicolumn{3}{|l|}{ Produto Ampliado } \\
\hline $\begin{array}{l}\text { Acessibilidade: Localização física; facilidade de localização } \\
\text { físico/visual; horários de funcionamento e vias de acesso. }\end{array}$ & Atende & $\begin{array}{l}\text { Atende } \\
\text { parcialmente }\end{array}$ \\
\hline $\begin{array}{l}\text { Atmosfera: Aparência física condizente com o destino (ambiente } \\
\text { hospitaleiro), guichê, tamanho, sons e banheiro }\end{array}$ & Atende & Não atende \\
\hline $\begin{array}{l}\text { Participação dos clientes: Atendentes com } 2^{\circ} \text { idioma, e-mail e redes } \\
\text { sociais. }\end{array}$ & Atende & $\begin{array}{l}\text { Atende } \\
\text { parcialmente }\end{array}$ \\
\hline $\begin{array}{l}\text { Interação dos clientes entre si: Espaço que proporcione interação entre os } \\
\text { usuários. }\end{array}$ & Atende & Não atende \\
\hline
\end{tabular}

Além da distribuição de material informativo e promocional o quiosque da rodoviária é utilizado pelos turistas para se informar sobre trajetos e itinerários de ônibus intermunicipais e interestaduais. Os CATs da Rodoviária Municipal e do Aeroporto de Confins foram os únicos que passaram por reformas completas nas suas estruturas físicas. É possível perceber que estes CATs seguiram o mesmo projeto, o que sugere que houve preocupação por parte dos gestores públicos com a padronização destes espaços.

Apesar da melhoria isolada de indicadores no que tange as categorias "produto suporte" e "produto ampliado", de forma geral fica claro que as principais limitações observadas nos CATs no período da Copa não foram solucionadas após 4 anos de realização do evento. Em alguns casos, inclusive, a situação foi agravada com uma significativa piora dos indicadores analisados. Por meio da analise do quadro geral da situação fica perceptível a preocupação em atender uma demanda especifica a época da Copa, porém, a importância da manutenção destes serviços não deveria ser tratado como pontual, uma vez que a atividade turística em Belo Horizonte, sobretudo, o turismo de negócios e eventos ocorre ao longo de todo $\mathrm{o}$ ano e tem no funcionamento e atendimento adequado dos CATs uma importante ferramenta de sustentação.

Dentre as três categorias analisadas é notório a significativa limitação no que se refere aos critérios da dimensão "produto suporte" o que denota fragilidade e descontinuidade entre os produtos turísticos de Belo Horizonte e da complementação entre as iniciativas de cunho público e privado. Além disso, percebe-se a ausência de padrão nos CATs quanto as facilidades oferecidas aos turistas.

A BELOTUR deixou de manter 3 CATs que eram de sua responsabilidade: o CAT da Rodoviária, dos Aeroportos da Pampulha e Confins. Outra perda observada foi que o Guia Turístico da cidade que era oferecido parou de ser distribuído. Atualmente os turistas recebem apenas um mapa da cidade.

\section{Estrutura Física e Bem-estar nos Centros de Atendimento ao Turista}

Nos CATs visitados tornou-se possível constatar que a única função estabelecida se refere à tirar dúvidas dos visitantes e distribuir material promocional. Dessa forma, os CATs atenderiam apenas uma das suas quatro funções básicas identificadas por Pearce (1991) e Moscardo (1998, 1999).

No que se refere ao perfil dos atendentes dos CATs, identificado a partir das entrevistas, foi observado que, em geral, é composto de estagiários, na maioria dos casos graduandos em Turismo, ou funcionários efetivos da BELOTUR. Assim, grande parte possui ensino superior incompleto. Os estagiários cumprem uma carga horária de trabalho de quatro horas por dia e os funcionários de oito horas. Foi possível observar que entre 2014 e 2018 esse quadro se manteve inalterado.

Apenas dois CATs ofereciam itens do "Produto Suporte": o do Mercado das Borboletas e do Aeroporto de Confins. Se considerar que apenas do CAT Mercado das Borboletas fica na área urbana de Belo Horizonte, com o seu fechamento a cidade 
perdeu o único lugar que oferecia aos visitantes e moradores o acesso a esses serviços.

Por fim, é importante ressaltar a necessidade de gerenciamento dos dados coletados nos CATs. Implementar sistemas de informação com aplicativos e gadgets são necessários e primordiais para tornar o destino inteligente, com o investimento na estruturação física, tecnológica e de gestão dos CATs. Sem uma estrutura de qualidade, mas, principalmente, sem uma gestão inteligente dos dados através de TICs, as políticas de turismo não serão arguciosas e irão demandar gastos desnecessários com consultorias. Portanto, os CATS devem ser locais próprios para as pesquisas e recebimento dos turistas e um local de gestão e compartilhamento de pesquisas da demanda turística.

Com o objetivo de elucidar a necessidade de alteração da funcionalidade atual dos CATs de Belo Horizonte, demonstrou-se, em uma recente pesquisa a real oferta de aplicativos móveis (Malta et al., 2018) que podem proporcionar aos visitantes as mesmas informações que oferece um atendente de um CAT. O público que atualmente utiliza dispositivos com acesso à internet e, portanto, à informação acessível em praticamente qualquer ponto da cidade, está em franca expansão.

É preciso mais do que competir com tais tecnologias. Para avançar, é preciso se utilizar de uma gestão de Tecnologias de Informação integrando os CATs e garantir um atendimento de qualidade e personalizado.

\section{Conclusão}

Com relação aos Centros de Atendimento ao Turista de Belo Horizonte, suas funcionalidades e investimentos, pode-se considerar que apresentam uma funcionalidade que, muitas vezes, não condiz com a teoria daquilo que se entende por um CAT, já que tendem a cumprir a função somente de informar o turista e não de cativá-lo a permanecer mais na cidade e conhecer outros atrativos ou serviços que a cidade oferece. É dever dos atendentes, portanto, a cada atendimento empreender esforços no sentido de promover a cidade de Belo Horizonte e seu entorno.

É difícil, porém, que este interesse dos atendentes em promover um atendimento de qualidade seja constante, e cabe a BELOTUR, como órgão público responsável pela gestão dos CATs, a responsabilidade de qualificar e treinar seus funcionários e estagiários constantemente para que estes sejam capazes de "atender" com qualidade e entusiasmo o turista, e incentivá-los a se interessar à cidade e aos atrativos que ela oferece. Não obstante, compreende-se a dificuldade dos órgãos públicos em viabilizar recursos humanos e financeiros para realizar tais atividades, mas, entende-se, a partir deste estudo, que o CAT poderia ser visto como um importante elemento afirmador da imagem perante o turista, sobretudo no seu contato inicial com a cidade.

O legado de imagem de uma cidade está associado, sobremaneira, à qualidade da experiência e à percepção que o visitante terá durante a sua visita, ou seja, se a experiência for positiva, é possível que o visitante volte, traga sua família, caso contrário, as percepções negativas se multiplicam entre aqueles que ainda não conhecem a cidade e, provavelmente, não irão querer conhecê-la.

Os investimentos que contemplaram ou visaram contemplar os CATs dizem respeito, sobretudo, à compra de mobiliário e equipamentos para estes espaços. É importante salientar, deste modo, que o investimento em qualificação dos profissionais que lá trabalham foi realizado somente com relação ao ensino de idioma estrangeiro para alguns deles. Considera-se que tal qualificação é importante, todavia, é insuficiente para atingir um nível de atendimento que condiz com uma cidade como Belo Horizonte, que possui como uma de suas principais metas tornar-se um destino internacional.

Os CATs, na sua totalidade, poderiam evoluir em sua funcionalidade aprimorando, principalmente, a qualidade do atendimento. A intenção deveria ser estimular os visitantes a conhecerem mais atrativos e locais de seu interesse e, assim, aumentar seu tempo de estada na cidade e diversificar a distribuição de seus gastos.

Apesar dos investimentos realizados e da expectativa que houve de um legado pós Copa do Mundo 2014 em relação ao CATs, pode-se dizer que essa expectativa não foi ainda de fato concretizada. A cidade de Belo Horizonte, ao analisar o conjunto das avaliações dos CATs, não teve melhoria significativa em nenhum dos itens avaliados entre 2014 e 2018. Vale ressaltar que o mesmo foi observado em análises de áreas que receberam investimentos em Belo Horizonte como os APPs de informação turística (Malta et al, 2018) e na sinalização turística (Barbosa et al, 2017).

Ademais, foi possível observar que não há uma produção acadêmica significativa sobre o tema e, por consequência, há poucos artigos em periódicos nacionais. Espera-se, portanto, que esse artigo possa servir de parâmetro de análise e possibilitar futuros estudos comparativos entre cidades brasileiras. 
Análise dos Centros de Atendimento ao Turista em Belo Horizonte/Minas Gerais/Brasil entre os Anos de

\section{Referências}

Barbosa, M. F. P.; Braga, S. S.; Malta, G. A. P. Análise da sinalização turística em Belo Horizonte/MG (2013-2014). (2017). Turismo, Visão e Ação, v. 19, n. 2, p. 348-374, 2017.

Barretto, M. (1997). Manual de iniciação ao estudo do turismo. 2.ed. Campinas: Papirus.

Beni, M. C. (2001). Análise estrutural do turismo. 6. ed. São Paulo: SENAC/SP.

Bissoli, M.A.M.A. (2002). Planejamento Turístico Municipal com suporte em sistema de informação. 2. ed. São Paulo: Futura.

Brasil. (2007). Plano Nacional do Turismo Diretrizes, metas e programas 2007 - 2010. Brasília, DF: Ministério do Turismo.

Brasil. (2009). Proposta Estratégica de Organização Turística Copa do Mundo 2014 Brasil. Ministério do Turismo; Fundação Getúlio Vargas. Brasília. Disponível em: http://www.turismo.gov.br/export/sites/default/turis mo/o_ministerio/publicacoes/downloads_publicacoe s/BRASIL_final_NOVO.pdf. Acesso em: 06/05/2014.

Carneiro, J. B., \& Fontes, N. D. (1997). Turismo e eventos: instrumento de promoção e estratégia de marketing. Turismo em Análise, 8(1), 63-74.

Castelli, G. (2003). Administração Hoteleira. Caxias do Sul: EDUCS.

Espigão, Helga S.; Silva, Bruna S.; Dias, Michelle G. (2012). Centros de Informações Turísticas: estudo de caso do OfficialTourism Centre na cidade de Dublin, Irlanda. Congresso Latino-Americano de Investigação Turística edição 5.: 2012: São Paulo, SP.

Ferreira, R. S., Wada, E. K. (2010). Eventos uma alavanca de negócios: como e por que implantar PEGE. São Paulo: Aleph.

Füster, L. F. (1985) Introduccion a la teoria y tecnicadel turismo. Madrid: Alianza.

Gohr, C. F.; Santos, L. C.; Veiga, M. F. (2009) A informação como elemento chave para a qualidade do produto turístico: uma análise dos postos de informações turísticas do município de Florianópolis/SC. Perspectivas em Ciência da Informação, v. 14, n. 2, p. 169 - 186, maio /ago. 2009.

Ignarra, L. R. (1999). Fundamentos do turismo. São Paulo: Pioneira.

Ishiy, Morupi. (1998). Turismo e megaeventos esportivos. Turismo em Análise, São Paulo, v. 9, n. 2, p. 47-61, nov.

Filho, V. Lucca. (2005). Estudo do fluxo de informações em centros de informações turísticas de Santa Catarina: Programa Portais do Lazer. (Dissertação de Mestrado). Florianópolis.

Malta, Guilherme Augusto Pereira; Braga, Solano De Souza; Perinotto, André Riani Costa; Barbosa, Maria Flávia Pires. (2018). Análise da oferta, uso e qualidade dos APPS de informação turística em Belo Horizonte - MG no período 2014-2017. Revista Marketing and Tourism Review.

Matias, M. (2007). Organização de eventos: procedimentos e técnicas. Editora Manole.

Mendes, D. A. T.; Wada, E. K. (2016). Copa 2014: As relações de hospitalidade e hostilidade ao visitante - Brasil. PODIUM Sport, Leisure and Tourism Review, v. 5, n. 1, p. 39-47, 2016.

Moscardo, G. (1998). Interpretation and sustainable tourism: Functions, examples and principles. Journal of Tourism Studies, v. 9, n. 2, p.13, Jun.

(1999). Making Visitors mindful: principles for creating sustainable visitors experiences through effective communication. Illinois, USA: SagamorePublishing.

Nascimento, Maria de J.; Silva, Paula S. (2004). Informação: insumo básico para o desenvolvimento do setor de turismo em Santa Catarina. Perspectivas em Ciência da Informação, Belo Horizonte, v. 9, n. 1, p. 48-69, jan./jun.

Oliveira, A. P. (2001). Turismo $e$ desenvolvimento: planejamento e organização. 3. ed. ver. e ampl. São Paulo: Atlas, 2001.

Organização mundial do turismo (OMT). (2004). Tourism and poverty alleviation recommendation for 
action. Madrid: World Tourism Organization.

Pearce, P. (1991). Visitor's centres and their function in the landscape of tourism. In: G. Moscardo. Ughes, K. (Orgs.) Visitor centres: exploring new territory. National Conference on Visitor Centres. Townsville, Australia: James Cook University, p. 138-143.

Phillips, J.J.; Myhill, M. \&Mcdnough, J.B. (2008). $O$ valor estratégico dos eventos: como e por que medir ROI. São Paulo: Aleph.

Piscopo, Marcos Roberto et al. (2015). O setor brasileiro de turismo: evolução, situação atual e perspectivas futuras. Podium Sport, Leisure and Tourism Review, v. 4, n. 1, p. 1-14, 2015.

Ruschmann, Doris Van De Meene. (1997). Turismo e Planejamento sustentável: A proteção do meio ambiente. Campinas, SP: Papirus.

Endereços eletrônicos Dicionário Aurélio Online (Disponível

em:

http://www.dicionariodoaurelio.com. Acesso em: 19/05/14.)

Portal da Copa. (Disponível em: http://www.copa2014.gov.br/pt-

$\mathrm{br} / \mathrm{brasilecopa/sobreacopa/matriz-responsabilidades.}$ Acesso em: 28/04/2014 as 15h40.)

Portal da Transparência (Disponível em: http://www.portaltransparencia.gov.br/copa2014/cid ades/home.seam?cidadeSede $=1$. Acesso em: 29/04/2014).
Portal da Transparência (Disponível em: http://www.portaltransparencia.gov.br/copa2014/cid ades $/$ tema.seam?tema $=4 \&$ cidadeSede $=1$. Acesso em: 29/04/2014).

Portal da Transparência (Disponível em: http://www.portaltransparencia.gov.br/convenios/Det alhaConvenio.asp? CodConvenio $=572353 \&$ TipoCon sulta $=0 \& U F=m g \&$ CodMunicipio $=4377 \&$ Municipio $=$ CORDISBURGO $\&$ CodOrgao $=\&$ Orgao $=\&$ Pagina $=$ $\&$ Periodo $=$ Acesso em: 07/05/2014).

Portal da Transparência (Disponível em: http://www.portaltransparencia.gov.br/copa2014/cid ades $/$ tema.seam?tema $=4 \&$ cidadeSede $=1$ Acesso em: $\underline{11 / 05 / 14)}$.

Portal da Transparência (http://www.portaldatransparencia.gov.br/convenios/ DetalhaConvenio.asp?CodConvenio $=770397 \&$ Tipo Consulta $=1 \& U F=m g \&$ CodMunicipio $=4123 \&$ Munici pio $=$ BELO $\% 20$ HORIZONTE $\&$ CodOrgao $=54000 \&$ Orgao $=$ ministerio $\% 20 \mathrm{do} \% 20$ turismo\&Pagina $=\&$ Peri odo=)http://repasse.turismo.gov.br/?pagina=pages $/ \mathrm{co}$ ntrato.php\&id $=0386790$

Ministério do Turismo. (Disponível em: http://repasse.turismo.gov.br/?pagina=pages/contrato .php\&id=0386790. Acesso em 11/05/14).

Prefeitura Municipal de Belo Horizonte: http://www.belohorizonte.mg.gov.br/categorias/locai s/servico-turistico/informacao-turistica/centro-deatendimento-ao-turista 